\title{
GEOTURISMO: UMA PROPOSTA DE TURISMO SUSTENTÁVEL E CONSERVACIONISTA PARA A REGIÃO NORDESTE DO BRASIL
}

\section{Geotourism: a proposal for conservation and sustainable tourism for the Northeast Region of Brazil}

\author{
Marcelo Martins Moura-Fé \\ Universidade Federal do Ceará, Fortaleza, Ceará, Brasil \\ mourafe.marcelo@yahoo.com.br
}

Artigo recebido em 05/10/2014 e aceito para publicação em 30/01/2015

RESUMO: O geoturismo se apresenta como um segmento promissor da atividade turística, relacionado ao ecoturismo, com características específicas e essenciais à conservação da geodiversidade, em consonância com diversos preceitos exigidos para o desenvolvimento econômico local das comunidades. O objetivo desse estudo é analisar o geoturismo e seus preceitos fundamentais e aplicáveis para o desenvolvimento do turismo sustentável e de caráter conservacionista na região Nordeste do Brasil, contemplando as dimensões estratégicas dessa atividade a curto, médio e longo prazos - a interpretação da paisagem e o fomento à educação ambiental; bem como, exemplos potenciais e efetivos de sua implementação existentes na região Nordeste. O geoturismo, junto com os demais ramos do turismo sustentável, aparece como uma real alternativa para o desenvolvimento da região Nordeste e para a melhoria das condições de vida das populações locais, desde que sua implementação se dê sob condições de esforços e investimentos. Além disso, uma outra política de desenvolvimento do turismo é necessária, uma atividade para além do litoral nordestino, fomentando o desenvolvimento de regiões do interior dos estados, nas zonas rurais dos municípios, contribuindo para uma maior integração regional.

Palavras-chave: Patrimônio Natural. Geodiversidade. Geoconservação. Geomorfossítios. Educação Ambiental.

ABSTRACT: Geotourism is presented as a promising segment of tourism, ecotourism related with specific and essential to the conservation of geodiversity, in line with many precepts required for local economic development community features. The aim of this study is to analyze the geotourism and its fundamental precepts and applicable to the development of sustainable tourism and nature conservation in the Northeast region of Brazil, contemplating the strategic dimensions of this activity in the short, medium and long term - the interpretation of the landscape and promoting environmental education, as well as actual and potential examples of your existing deployment in the Northeast region. Geotourism, along with the other branches of sustainable tourism, appears as a real alternative for the development of the Northeast region and to improve the living conditions of local populations, since their implementation will take under conditions of efforts and investments. In addition, another policy of tourism development, an activity beyond the northeastern coast, fostering the development of the interior regions of the states, the municipalities in rural areas, contributing to greater regional integration is necessary.

Key-Words: Natural Heritage. Geodiversity. Geoconservation. Geomorphosites. Environmental Education. 


\section{INTRODUÇÃO}

Aregião Nordeste do Brasil vem desenvolvendo um quadro socioeconômico em que a atividade turística apresenta-se como um importante vetor de crescimento. Por sua vez, embasado fortemente no segmento "sol e praia" que se caracteriza, muitas vezes, como sazonal e massivo, tanto no litoral como nas águas/corpos d'água interiores, o turismo contribui, em muitos casos, para a perda de qualidade ambiental e para o desgaste da imagem de destinos turísticos.

Contudo, nas últimas décadas o turismo vem passando por um processo de segmentação de mercado, fundamentado na divisão da demanda ou da oferta, em função de suas características intrínsecas. Dentro do que se convencionou englobar sob a denominação de "turismo sustentável" estão o turismo de aventura, turismo rural, o ecoturismo e, menos conhecido, o geoturismo (CAVALCANTE e FURTADO, 2011; LOBO et al., 2012; MOREIRA, 2010; NASCIMENTO et al., 2007).

O geoturismo emerge como um expoente relacionado ao ecoturismo, inserindo um enfoque mais voltado ao ambiente físico, abiótico e, em muitos casos (como nas propostas de geoparques, como veremos adiante), buscando atender preceitos de sustentabilidade que o ecoturismo não atingiu por meio de suas práticas (LOBO et al., 2012).

O relativo quadro de desconhecimento desse segmento turístico aos poucos vem sendo redesenhado, tendo em vista que, conforme Bento e Rodrigues (2013), os primeiros passos na divulgação do geoturismo são visíveis quando se percebe a quantidade de eventos que vem sendo realizados, bem como a criação de projetos e programas voltados exclusivamente à valorização e divulgação do patrimônio natural, mais especificamente, a geodiversidade.

Aliás, a geodiversidade, enquanto testemunho científico dos acontecimentos que marcaram a história evolutiva da Terra, deve ser conservada como parte fundamental do patrimônio natural e utilizada para fins científicos, didáticos, culturais e geoturísticos (GODOY et al., 2013), apresentando 07 (sete) valores fundamentais, segundo Gray (2004): valor intrínseco, cultural, estético, econômico, funcional, científico e didático (MOCHIUTTI et al., 2012).

Neste contexto, o geoturismo tem se apresentado como um segmento promissor da atividade turística, ao apresentar características específicas e essenciais à conservação da geodiversidade, em consonância com diversos preceitos exigidos para o desenvolvimento econômico local das comunidades que podem e devem ser envolvidas (LOPES et al., 2011).

Desta forma, o objetivo desse estudo é analisar o geoturismo e seus preceitos fundamentais e aplicáveis para o desenvolvimento do turismo sustentável e de caráter conservacionista na região Nordeste do Brasil, contemplando as dimensões estratégicas dessa atividade a curto, médio e longo prazos, bem como, apresentar exemplos potenciais e efetivos de sua implementação existentes na região.

\section{MATERIAIS E MÉTODOS}

A natureza da pesquisa fundamentou-se em uma abordagem de cunho qualitativo, que de acordo com Gil (1996) visa a compreensão ou interpretação de processos de forma complexa e contextualizada e se caracteriza como um plano aberto e flexível. Quanto aos fins, esta investigação se caracterizou como descritiva.

No tocante às técnicas de pesquisa, os procedimentos desenvolvidos foram baseados em dois meios: o bibliográfico, com a realização de um estudo sistematizado, investigando materiais publicados, sobretudo, em periódicos de revistas científicas estrangeiras e nacionais, com levantamento dos principais referenciais teóricos e metodológicos; o de levantamentos de campo, os quais foram realizados pelo autor em diversos momentos na caracterização básica do patrimônio natural da Região Nordeste do Brasil.

\section{Conceituações}

Antes de avançarmos na discussão proposta, é importante apresentar conceituações básicas para o entendimento dos temas que compõem a análise realizada, como por exemplo, a distinção básica entre ecoturismo e geoturismo. 
Inicialmente, o que diferencia o ecoturismo do turismo convencional, conforme Moreira (2010), é o fato do primeiro ser considerado uma segmentação turística ambientalmente responsável, que cumpre critérios e princípios básicos de sustentabilidade. O geoturismo também segue essas premissas, mas contemplando como seu principal atrativo turístico a geodiversidade, cujo cerne integra a diversidade geológica (rochas, minerais e fósseis), geomorfológica (formas de relevo) e pedológica (solos), além dos processos que thes originaram (BÉTARD et al., 2011).

Aliás, por mais que diversas definições de ecoturismo contenham o patrimônio natural, nenhuma delas abrange a geodiversidade como parte do produto turístico, citando muitas vezes apenas a biodiversidade e a conservação dos elementos biológicos (fauna e flora) (MOREIRA 2010; NASCIMENTO et al., 2007; VIEIRA e CUNHA, 2004), uma lacuna que, por exemplo, prejudicou a contemplação da geodiversidade no estabelecimento da maior parte das unidades de conservação brasileiras.

Foco da atividade geoturística, a geodiversidade tem sua origem incerta. Entretanto, sabe-se que ela começou a ser efetivamente divulgada a partir do século XX, principalmente com a Conferência de Malvern sobre Conservação Geológica e Paisagística que ocorreu no Reino Unido em 1993 (BENTO e RODRIGUES, 2010).

Geodiversidade é, em linhas gerais, o conjunto de elementos geológicos e geomorfológicos da paisagem (ARAÚJO, 2005) envolvendo os aspectos abióticos da Terra, que por sua vez, são evidências dos processos passados e atuais. Assim, a geodiversidade é o resultado da interação de diversos fatores como as rochas, o clima, os seres vivos, entre outros, possibilitando o aparecimento de paisagens distintas em todo o mundo (BRILHA, 2005).

Com base nisso, o geoturismo objetiva a valorização e a conservação da geodiversidade dos lugares sob três motivações: recreação, lazer e aprendizado (BENTO e RODRIGUES, 2009; 2010; SOUSA e NASCIMENTO, 2007).

Conceitualmente, o geoturismo é a atividade do turismo com conotação geocientífica, ou seja, a visita organizada e orientada a locais onde ocorrem recursos do meio físico que testemunham uma fase do passado ou da história de origem e evolução do planeta Terra e que, por conseguinte, se notabilizam como uma herança coletiva e que deve ser preservada para as gerações futuras. Também se inclui, neste contexto, o conhecimento científico sobre a gênese da paisagem, os processos envolvidos e os testemunhos registrados em rochas, relevos e solos (SILVA e PERINOTTO, 2007; VIEIRA e CUNHA, 2004).

Com esse escopo, conforme Dowling (2011), o geoturismo oferece uma oportunidade para muitos países e regiões promoverem e divulgarem uma identidade que é única para cada lugar, ganhando atratividade e propiciando a excelência no turismo em consonância com a conservação da geodiversidade, beneficiando ainda as comunidades locais, conforme nuances particulares.

Ao possibilitar aos turistas não só contemplar a paisagem natural, mas acima de tudo, interpretar e entender os processos geológico-geomorfológicos responsáveis por sua formação, o geoturismo apresenta-se como uma atividade turística importante na conservação e sustentabilidade locais, também por meio de ações de educação ambiental (DEGRANDI e FIGUEIRÓ, 2011; NASCIMENTO et al., 2007).

Aliás, as duas dimensões estratégicas da atividade geoturística: a interpretação da paisagem e o fomento à educação ambiental projetam sua finalidade maior de conservação do patrimônio natural para duas escalas temporais diferentes, as quais serão discutidas a seguir.

\section{Geoturismo no cotidiano - conservando hoje}

A sociedade e a opinião pública mostram um interesse cada vez maior em relação às temáticas relacionadas com o meio ambiente e sua proteção, notadamente em virtude do agravamento das condições ambientais provocadas pelas atividades humanas e agressões perpetradas sobre a natureza.

Porém, a importância atribuída à proteção ambiental não é, de maneira geral, acompanhada da consciência do valor do patrimônio natural e da sua importância enquanto recurso ambiental, turístico ou mesmo, enquanto suporte fundamental da vida e das atividades humanas. Isso se reflete na exígua consideração por este tipo de patrimônio por parte 
das elites governamentais, o que vem condicionando o desenvolvimento ainda incipiente de políticas de promoção, de preservação e de divulgação desse segmento turístico (VIEIRA e CUNHA, 2004).

À revelia desse quadro, duas posturas mais que justificam as ações de preservação do patrimônio natural. A primeira, de ordem ética, fundamenta-se em um imprescindível valor humano, no respeito e na solidariedade que o ser humano, única criatura capaz de conhecer e compreender os fenômenos materiais e imateriais do universo, deve às diferentes formas de vida com as quais compartilha o espaço e o tempo. A segunda, de cunho pragmático, que se origina a partir do interesse e dependência da sociedade pelos recursos da natureza sem os quais não pode subsistir. A preservação dos recursos naturais assegura ao homem a possível fruição desses bens, mesmo que ainda não conheça suas possíveis formas de utilização (DELPHIM, 2004).

Nesse contexto, os primeiros relatos a respeito da importância e proteção do patrimônio natural, mais precisamente, abiótico, estão associados ao grupo "Lista Indicativa de Sítios Geológicos" (Global Indicative List of Geological Sites - GILGES) que propôs modificações nas diretrizes existentes até então para Sítios do Patrimônio Mundial (World Heritage Sites) da Organização das Nações Unidas para a Educação, a Ciência e a Cultura - UNESCO (United Nations Educational, Scientific and Cultural Organization), inserindo as propriedades geológicas afetadas como objeto daquele projeto (MEDEIROS e OLIVEIRA, 2011).

Em consequência, ainda segundo Medeiros e Oliveira (2011), surgem os primeiros projetos de geoconservação (conservação da geodiversidade) associados a instituições como a "União Internacional das Ciências Geológicas" (International Union of Geological Sciences - IUGS), que desenvolveu o Geosites (método de geoconservação vinculado a World Natural Heritage da UNESCO); a "Associação Europeia para Conservação do Patrimônio Geológico" (ProGEO); a "Sociedade Geológica Sul-Africana"; a "Comissão Brasileira de Sítios Geológicos e Paleontológicos" (SIGEP); e a "Iniciativa de Sofia para a Preservação da Diversidade Mineral". Este último englobava também a possibilidade de conservação ex-situ, isto é, a partir de coleções em museus.

Junto desses projetos, o geoturismo pode promover a geoconservação em todos os lugares que o possuam, bem como, dialética e obviamente, a geoconservação pode promover o geoturismo, ao proporcionar aos turistas uma visão mais científica do que contemplativa da paisagem (BENTO e RODRIGUES, 2010).

Num ciclo positivo, o geoturismo possibilita a promoção da geoconservação e esta, por sua vez, constitui-se como uma ferramenta indispensável na conservação da geodiversidade. Além disso, conforme Bento e Rodrigues (2013), geoturismo e geoconservação podem também ser tomados como indutores do desenvolvimento econômico local, propiciando a gestão e utilização da geodiversidade, desde que realizada de forma planejada e sustentável.

Apesar de integrar os documentos oficiais da UNESCO, de ser objeto de diversas pesquisas em nível global (MOREIRA 2010) e da sua notória importância para a geoconservação, o geoturismo ainda está longe de fazer parte do cotidiano das pessoas, inclusive daquelas que estão habituadas e têm acesso a realização de viagens turísticas com regularidade.

Provavelmente, de acordo com Moreira (2010), as pessoas viajam mais para ver belezas cênicas (montanhas, cachoeiras, cânions e diversos tipos de formações rochosas) do que para ver plantas e animais em particular (exceções para os casos das visitações feitas às reservas animais da África, santuários de baleias etc.). Entretanto, para muitos turistas, as rochas e suas formas correlatas não despertam a mesma atenção do que uma floresta, em virtude do movimento, coloração, sons e interação (MOREIRA, 2008; 2010).

Ainda assim, mesmo não possuindo conhecimentos geológico-geomorfológicos, muitas pessoas apresentam curiosidade e interesse nesses aspectos fundamentais da paisagem, na interpretação da paisagem, o que pode ser disponibilizado pelo geoturismo, possibilitando um verdadeiro "salto" na relação de inúmeros turistas com a natureza, ao passar da apreciação da paisagem para uma busca por sua compreensão, passível de ser realizada com o auxílio de meios interpretativos (MOREIRA, 2010) 
que podem ser realizados sob as mais diversas formas e estratégias.

Não custa frisar que as geociências são a base do geoturismo e que, por meio da sensibilização do turista, se busca a proteção de determinada área por meio da conservação de seus recursos, utilizando para isto a interpretação deste patrimônio, desta geodiversidade, tornando-o acessível ao público leigo, ao mesmo tempo, promovendo e divulgando o desenvolvimento das Ciências da Terra (ROCHA e NASCIMENTO, 2007).

Mas, para despertar o interesse dos turistas e trazê-los aos locais, é imprescindível tornar esses atrativos visíveis, acessíveis e passíveis de interesse e entendimento, o que não é algo que possa ser categorizado como "fácil". Isso se deve à complexidade embutida na história evolutiva de inúmeros lugares (numa equação simples: quanto mais rica a história maior sua complexidade) e na tradução da linguagem científica para uma linguagem adequada para o cidadão comum, não-especialista.

Nesse contexto, a interpretação ambiental (e evolutiva, frise-se) deve ser entendida como a arte de explicar o significado de determinado recurso ou atrativo turístico, e tem por objetivo "proporcionar o entendimento do ambiente natural, despertar a atenção e o interesse do visitante em relação à natureza e à cultura, direcionando o olhar do turista, pois os ambientes não falam por si, precisam ser traduzidos" (BRASIL, 2010, p. 27).

Especificamente em relação ao alcance desse entendimento por parte do público alvo, as estratégias devem ser implementadas, inicialmente, tendo como base uma diferenciação básica entre público geral, dotado de turistas e visitantes locais, com formações variadas e sem necessidade de um aprofundamento científico acentuado; e pelo público específico, com necessidades maiores em termos de conteúdos científicos com informações diferenciadas, mais acentuadas, enfim, dotado de maior capacidade de assimilação (VIEIRA e CUNHA, 2004).

Desta forma, é fundamental que a elaboração de textos explicativos sejam feitos direcionados para ambos os grupos, em versões adequadas e, claro, elaborados por profissionais qualificados para realizarem essa decodificação da paisagem, que é, em sua essência, um trabalho científico. Exemplos práticos dessas diferentes linguagens podem ser vistos nos textos disponibilizados pela SIGEP para descrição dos geossítios em sua página web (http://sigep.cprm. gov.br/sitios.htm).

Contemplada essa etapa, o trabalho de divulgação é premente. Como estímulo para que as visitas ocasionais transformem-se em eventos agendados, planejados e desejados por um número cada vez maior de pessoas, conforme Moreira (2010), o estabelecimento de redes de comunicação e a troca adequada de informações, em suma, uma verdadeira divulgação turística, é muito importante. Além dos canais tradicionais de transmissão (revistas especializadas, livros, programas de televisão, de rádio etc.), deve haver um investimento sério e planejado nos meios multimídia, sobretudo a internet, indispensável nos processos de globalização de ideias e iniciativas de sensibilização e divulgação do patrimônio natural, da geodiversidade, dos locais e seus atributos, enfim, estimulando, a "fome de conhecimento" (VIEIRA e CUNHA, 2004).

O estímulo e o desenvolvimento do geoturismo por meio da interpretação da paisagem tendem a fomentar o crescimento do número de pessoas sensíveis e interessadas em conhecer e preservar o patrimônio natural tanto dos lugares visitados quanto, de forma mais ampla, dos lugares reconhecidos em qualquer lugar do país e do mundo, obtendo um efeito praticamente instantâneo para a conservação do patrimônio natural e sua geodiversidade.

\section{Fomento à educação ambiental - conservando para o futuro}

Ampliar a rede de pessoas interessadas na geoconservação e na atividade geoturística é importante, mas, para que isso ocorra de forma mais contundente, ampla e profunda, a segunda dimensão estratégica do geoturismo e de maior amplitude temporal (médio e longo prazos), é fundamental: a educação ambiental.

Conforme $\mathrm{o}$ art. $1^{\circ}$ da Lei Federal $\mathrm{n}^{\circ}$ 9.795/1999 (que dispõe sobre a educação ambiental, institui a Política Nacional de Educação Ambiental e dá outras providências): 
Entendem-se por educação ambiental os processos por meio dos quais o indivíduo e a coletividade constroem valores sociais, conhecimentos, habilidades, atitudes e competências voltadas para a conservação do meio ambiente, bem de uso comum do povo, essencial à sadia qualidade de vida e sua sustentabilidade (BRASIL, 1999).

Nesta perspectiva, a lei reconhece a educação ambiental como um componente essencial e permanente em todo o processo educativo, formal e/ ou não formal, como orientam os Artigos 205 e 225 da Constituição Federal do Brasil (SILVA, 2003).

Segundo essa lei, um dos objetivos da educação ambiental é o "incentivo à participação individual e coletiva, permanente e responsável, na preservação do equilíbrio do meio ambiente, entendendo-se a defesa da qualidade ambiental como um valor inseparável do exercício da cidadania" (BRASIL, 1999, art. $5^{\circ}$ ). Dito isto, fica claro o propósito de alcance de longo prazo, embutido na essência dessa modalidade educativa.

A importância da estratégia de divulgação e sensibilização junto ao público estudantil se dá pelo fato desse segmento da sociedade ser mais aberto a esse tipo de iniciativa e com uma capacidade de interiorização de mensagens de caráter ambiental mais acentuada. Além disso, Vieira e Cunha (2004) apontam para a importância de se tratar os conteúdos pertinentes ao patrimônio natural nos níveis mais básicos da educação, integrando-os aos currículos disciplinares.

Outras propostas, de cunho mais prático, relacionando a educação ambiental com as atividades geoturísticas direcionadas para a classe discente são: a implementação de centros de interpretação natural ou ambiental, com infraestrutura de apoio ao público, material impresso, painéis interpretativos, vídeos, jogos, atividades lúdicas (como escaladas), museus, palestras, exposições, adoção da prática dos conteúdos de sala em trabalhos de campo, concepção e implementação de trilhas e percursos educativos e turísticos, excursões e visitas guiadas, asseguradas por técnicos com capacidade adequada e formação científica, e pela dotação de espaços em que se enquadram os elementos patrimoniais em condições de identificação e informação para os visitantes (ALMEIDA e PORTO JUNIOR, 2012; LOPES et al., 2011; RUSS e NOLASCO, 2012; VIEIRA e CUNHA, 2004).

A partir desse viés educativo se possibilita a valoração e valorização da geodiversidade a longo prazo, gerando um sentimento de respeito e corresponsabilidade pela manutenção da conservação ambiental (BENTO e RODRIGUES, 2013) e que, se pensado e aplicado de forma ampla e consistente, pode perdurar por mais tempo ao se inserir no cotidiano das gerações futuras.

Obviamente, são necessárias melhorias no sistema de ensino, incluindo o campo de geociências, mas, sem dúvida, conforme Piranha et al. (2011), esta é uma das melhores estratégias para a conservação do patrimônio natural e cultural também, ao passo que as mudanças na educação, sem dúvida, podem alcançar mudanças profundas e autossustentáveis em outras áreas. No entanto, este processo não irá produzir resultados rápidos: exige tempo, investimento, estratégias, e acima de tudo, vontade política.

Aliás, qualquer política de conservação do patrimônio, exige antes o mais vasto reconhecimento social possível (LUGON et al., 2006), e qual a forma mais vigorosa para que isso ocorra senão pela educação das pessoas?

\section{Exemplos potenciais}

No mundo, diversos estudos vêm sendo desenvolvidos e divulgados, apontando áreas potenciais em diversos locais para a efetivação do geoturismo, como por exemplo, na Austrália (JOYCE, 2010), na Polônia (ZGŁOBICKI e BARANZGŁOBICKA, 2013), em Portugal (PEREIRA et al., 2007), na Itália (BORGATTI e TOSATTI, 2010; CORATZA e WAELE, 2012; LUGERI et al., 2011; MICCADEI et al., 2011; PANIZZA, 2001; PANIZZA e PIACENTE, 2008) e na Espanha (CARCAVILLA et al., 2009; FUERTES-GUTIÉRREZ e FERNÁNDEZMARTÍNEZ, 2010; PELLITERO et al., 2011).

O Brasil possui amplo potencial para o desenvolvimento do geoturismo em todos os seus grandes domínios paisagísticos que incluem regiões florestadas da Amazônia, chapadões do Brasil central 
e, dentre outros, o semiárido da sua Região Nordeste, cada um deles rico em sítios e paisagens peculiares, do mais elevado valor estético, cultural, científico, "repositórios de informações e significados que apenas o ser humano pode decifrar" (DELPHIM, 2004, p. 8). Um patrimônio imenso ainda insuficientemente conhecido e pouco protegido e que é a matéria-prima do geoturismo (BENTO e RODRIGUES, 2011).

$\mathrm{O}$ geoturismo pode ser realizado em locais com quedas d'água, cavernas, cursos d'água, afloramentos rochosos, falésias (BENTO e RODRIGUES, 2011), além de serras, chapadas, lajedos, promontórios, boqueirões, campos de dunas, afloramentos de paleodunas, manguezais, lagoas, fontes e nascentes, entre muitos outros.

Estudos realizados no Brasil citam vários lugares potenciais, por vezes, já estruturados e conhecidos no ramo do turismo mais convencional (segmento sol e praia, por exemplo), como o município de Icapuí, no Ceará (SOUSA et al., 2009; SOUSA e NASCIMENTO, 2007), nas serras úmidas da região Nordeste, como a Chapada do Araripe e a Serra da Ibiapaba, dentre outras (BÉTARD et al., 2011), que podem ser perfeitamente utilizados para as práticas geoturísticas desde que sejam realizadas adaptações.

Vale informar que diversos locais potenciais já foram identificados e devidamente reconhecidos pelo SIGEP, inclusive com a importante etapa de interpretação da paisagem já realizada por autores competentes. Dentre esses sítios de elevado valor patrimonial e que ilustram a relevância da geodiversidade nordestina, podemos citar:

- Os estratos calcários identificados em Paulista (PE), que apresentam evidências de evento catastrófico no primeiro registro do limite K-T (CretáceoTerciário) descrito na América do Sul (ALBERTÃO e MARTINS JR., 2009);

- Os arrecifes da capital pernambucana, um importante registro holocênico do nível relativo do mar acima do atual (BARRETO et al., 2009);

- $\quad$ A Pedra furada de Venturosa (PE), um raro arco granítico com enclaves dioríticos (MARIANO et al., 2009);

- Os icnofósseis da Bacia do Rio do Peixe (PB), considerado o mais marcante registro de pegadas de dinossauros do Brasil (LEONARDI e CARVALHO,
2002);

- O mar de bolas do Lajedo do Pai Mateus, em Cabaceiras (PB), um campo de matacões graníticos gigantes e registros rupestres de civilização précolombiana (LAGES et al., 2009);

- O Lajedo de Soledade, no município de Apodi (RN), caracterizada pela ocorrência peculiar de megafauna fóssil quaternária no Nordeste do Brasil (PORPINO et al., 2009; SANTOS et al., 2002);

- O Pico do Cabugi (RN), registro do mais jovem magmatismo continental do Brasil (FERREIRA e SIAL, 2002; ROCHA e NASCIMENTO, 2007);

- $\quad$ O registro de geleiras continentais há 360 milhões de anos no Nordeste do Brasil, identificado em Calembre, Brejo do Piauí (PI) (CAPUTO e PONCIANO, 2009);

- $\quad$ O afloramento fossilífero de Oiti, verificado na Bacia do Parnaíba (PI), um registro de um mar devoniano no Nordeste do Brasil (PONCIANO et al., 2009).

- O Parque Nacional de Sete Cidades (PI), considerado um magnífico monumento natural (FAVERA, 2002);

- $\quad$ A Chapada do Araripe (modelado situado na região sul do Ceará) (KELLNER, 2002; VIANA e NEUMANN, 2002);

- APonta de Jericoacoara (Jijoca de Jericoacoara, CE), belo promontório de rochas neoproterozoicas associadas a praias e dunas quaternárias com registros de variações do nível do mar (JULIO et al., 2009);

- Os eolianitos de Flecheiras/Mundaú (Trairi, CE), um registro ímpar de um paleo-sistema eólico costeiro (CARVALHO et al., 2009);

- Os tanques fossilíferos de Itapipoca (CE), registros de bebedouros e cemitérios de megafauna pré-histórica (XIMENES, 2009); e, por fim,

- Os inselbergues de Quixadá (CE), em parte protegidos legalmente pelo Monumento Natural Monólitos de Quixadá (UC estadual de proteção integral), que constituem um geossítio aprovado pela SIGEP (ainda não publicado), e que fazem parte de um geoparque proposto, o Vale Monumental (SCHOBBENHAUS e SILVA, 2012).

Não é difícil deduzir que, baseados nos excepcionais exemplos citados, a região Nordeste 
possui diversos locais com potencial significativo para a prática do geoturismo, os quais, aliás, necessitam da proteção que a atividade turística sustentável pode dar.

Em uma situação melhor estão as áreas naturais legalmente protegidas, com destaque para as unidades de conservação (UCs), principalmente os parques nacionais (CAVALCANTE e FURTADO, 2011), os quais, em número considerável, possuem os atrativos e a estrutura básica para o geoturismo. Contudo, conforme Bento e Rodrigues (2013), há de se ressaltar a necessidade desse segmento ser planejado, buscando uma utilização mais racional dos recursos da geodiversidade, garantindo a viabilidade do geoturismo e a manutenção das unidades de conservação abertas à visitação pública, o que efetivamente não é feito.

Ressalvando-se esse aspecto, ao se estimular o desenvolvimento do geoturismo nas UCs, de forma integrada aos demais segmentos já existentes, contribui-se para a ampliação do tempo de permanência dos turistas, permitindo, consequentemente, mais renda para o centro receptor (BENTO e RODRIGUES, 2013).

Além da utilização das UCs, vale frisar a Rede Mundial de Geoparques, sob os cuidados da UNESCO, que recomenda que nestas áreas o geoturismo seja reconhecido e amplamente difundido e valorizado. Este é um dos indícios mais importantes de que essa temática vem ganhando espaço, saindo do universo das academias e sendo aplicado no cotidiano atual da sociedade (BENTO e RODRIGUES, 2013; NASCIMENTO et al., 2007).

Geoparque é uma marca atribuída pela UNESCO a uma área onde sítios do patrimônio geológico representam parte de um conceito holístico de proteção, educação e desenvolvimento sustentável. Um geoparque deve gerar atividade econômica, notadamente através do turismo, e envolve um número de sítios geológicos de importância científica, raridade ou beleza, incluindo formas de relevo e suas paisagens (SCHOBBENHAUS e SILVA, 2012).

Um geoparque no conceito da UNESCO deve:

- preservar o patrimônio geológico para futuras gerações (geoconservação);

-educar e ensinar o grande público sobre temas geológicos e ambientais e prover meios de pesquisa para as geociências;

- assegurar o desenvolvimento sustentável através do geoturismo, reforçando a identificação da população com sua região, promovendo o respeito ao meio ambiente e estimulando a atividade socioeconômica com a criação de empreendimentos locais, pequenos negócios, indústrias de hospedagem e novos empregos;

- Gerar novas fontes de renda para a população local e a atrair capital privado.

Por outro viés, em uma escala mais regional, Estados do Brasil e, mais especificamente, da região Nordeste, já vêm trabalhando em projetos voltados ao planejamento e divulgação do potencial do geoturismo. Por exemplo, em Pernambuco, um curso para condutores de geoturismo foi realizado em Fernando de Noronha em 2007; o "Projeto Monumentos Geológicos" do Rio Grande do Norte, e o "Projeto Caminhos Geológicos", na Bahia (LOPES et al., 2011; MOREIRA 2010), reforçando o quadro de crescimento do geoturismo na região.

\section{Geopark Araripe: um modelo a ser seguido}

O Geopark Araripe situa-se na região sul do Ceará, pertencendo aos municípios de Santana do Cariri, Nova Olinda, Crato, Juazeiro do Norte, Barbalha e Missão Velha. O Geoparque foi criado em 2006, sendo o único das Américas e do hemisfério sul, e está inserido na Chapada do Araripe e na Região do Complexo Sedimentar do Araripe (ALVES et al., 2010).

Este geoparque possui 9 geossítios abertos para visitação, a saber: 1 - Geossítio Pontal da Santa Cruz, 2 - Geossítio Riacho do Meio, 3 - Geossítio Colina do Horto, 4 - Geossítio Pedra Cariri, 5 - Geossítio Ponte de Pedra, 6 - Geossítio Parque dos Pterossauros, 7 Geossítio Cachoeira de Missão Velha, 8 - Geossítio Floresta Petrificada, 9 - Geossítio Batateira; além de um geossítio desativado por questões ambientais, o Geossítio Ipubi (BRITO e PERINOTTO, 2012).

Tal diversidade pode ser ainda mais abrangente, já que, como frisam Brito e Perinotto (2012), existem mais geossítios localizados na Região do Complexo Sedimentar do Araripe e na Chapada do Araripe, 
ultrapassando as fronteiras do Geopark Araripe, e que os mesmos ainda não estão inventariados e encontramse ausentes de um plano de conservação e gestão para a ampliação deste território ou do fluxo de visitantes.

Em que pese a necessidade de ampliação de seus limites, o Geopark Araripe já possui ambientes de grande relevância científica, educacional e didática, o quadro básico para que a atividade geoturística seja desenvolvida, um segmento fundamental para as atividades do geoparque.

Desta forma, para as atividades do Geopark Araripe, a associação entre os atrativos turísticos locais com as informações cientificas favorecem a difusão das Ciências Exatas e da Terra, se diferenciando de outros destinos turísticos nacionais e internacionais, por fomentar a conservação, a educação e o turismo em um território, e oferecer o patrimônio geológico como atrativo principal (BRITO e PERINOTTO, 2012).

Contudo, para que haja a sua efetiva utilização, é importante que ocorra o engajamento na rede global de geoparques, o que permite a troca de ideias, experiências e melhores práticas, facilitando cumprir seus objetivos comuns: a conservação do patrimônio natural (geológico e biológico), cultural, educação, e desenvolvimento da economia local, através do geoturismo (FARSANI et al., 2012).

Do ponto de vista socioeconômico, como os geoparques estão localizados em áreas rurais, a conjunção entre geoparques e o geoturismo vêm fomentando oportunidades para o desenvolvimento de zonas rurais, o que vem sendo viabilizado em diversos lugares do mundo onde as autoridades responsáveis pelos geoparques tomaram algumas políticas positivas para estimular os habitantes locais na participação de atividades, direcionando diversas regiões à prosperidade da economia local e da preservação dos recursos naturais (FARSANI et al., 2011).

Assim, considerando a importância da geoconservação, a qual é viabilizada pelas estratégias intrínsecas ao geoturismo e, sobretudo, à ampla possibilidade de efetivação dessa modalidade turística sustentável oferecida pelos geoparques, esse modelo pode e deve ser ampliado na Região Nordeste, embora necessite de maior apoio para que suas potencialidades sejam postas em prática.

Um projeto importante nesse ensejo é o
Projeto Geoparques, criado pela CPRM em 2006, com a finalidade de exercer um papel indutor na criação de geoparques no Brasil, através da identificação, levantamento, descrição, inventário, diagnóstico e ampla divulgação de áreas com potencial para futuros geoparques no território nacional.

Em 2012, a CPRM publicou o primeiro volume do livro sobre propostas de geoparques, das quais 14 relacionam-se ao Projeto Geoparques, dentre as quais 5 propostas concluídas são relacionadas à Região Nordeste: 1- Geoparque Fernando de Noronha (PE) (WILDNER e FERREIRA, 2012), 2- Geoparque Litoral sul de Pernambuco (PE) (NASCIMENTO et al., 2012), 3- Geoparque Morro do Chapéu (BA) (ROCHA e PEDREIRA, 2012), 4 - Geoparque Seridó (RN) (NASCIMENTO e FERREIRA, 2012) e, 5 Geoparque Serra da Capivara (PI) (BARROS et al., 2012).

\section{CONCLUSÕES}

O patrimônio natural, seja onde for, precisa ser protegido antes que se perca, mas isso somente se dará somente através do reconhecimento e da valoração desses recursos, que passam pelo planejamento de um turismo sustentável e condizente com esses objetivos.

$\mathrm{O}$ geoturismo está diretamente relacionado a essa necessária conservação do patrimônio natural, mais especificamente, em relação à geodiversidade, relegada, de certa forma, pela ênfase dada aos elementos mais ecológicos da paisagem (fauna e flora), e que precisa de maior atenção, face sua importância e enorme contribuição para o conhecimento da história do nosso planeta.

Alicerçado nas suas estratégias fundamentais, de interpretação da paisagem e de fomento à educação ambiental, o geoturismo aponta para a geoconservação em curto, médio e longos prazos, o que pode garantir um quadro mais promissor e mais longevo para a geoconservação.

As Unidades de Conservação e, sobretudo, os geoparques, se apresentam como locais propícios para que essa modalidade turística sustentável seja efetivada, mas precisam de adaptações e melhorias em suas estruturas, as quais devem ser voltadas para as particularidades da atividade geoturística (interpretação 
da paisagem e fomento à educação ambiental), o que só pode ser garantido com maior apoio.

Para além dessa importância científica e educacional, o geoturismo pode proporcionar a geração de empregos diretos e indiretos, os quais podem ser, majoritariamente, de ordem local, garantindo crescimento econômico para as localidades, apontando para um indicativo daquilo que muitos denominam de "desenvolvimento sustentável".

Nesse contexto, esse ramo novo da atividade turística pode chegar a assumir um grau de importância estratégica para o futuro do desenvolvimento turístico do Brasil, como um fator de desenvolvimento social, de educação ambiental e de valorização do potencial das comunidades envolvidas, além do marketing a nível regional, nacional e, porque não, internacional.

Por fim, não é exagero apontar que o geoturismo, junto com os demais ramos do turismo sustentável, aparece como uma real alternativa para o desenvolvimento da região Nordeste e para a melhoria das condições de vida das populações locais, desde que sua implementação se dê sob condições de esforços e investimentos, tais como: estradas, hospedagem, material de informação e interpretação etc.

Além disso, uma outra politica de desenvolvimento do turismo é necessária, uma atividade que se dê longe dos resorts e outras instalações cada vez mais presentes no litoral nordestino, fomentando o desenvolvimento, muitas vezes, de regiões do interior dos estados, contribuindo para uma maior integração regional. A pergunta que fica é: haverá vontade política para isso?

\section{AGRADECIMENTOS}

A Fundação Cearense de Apoio ao Desenvolvimento Científico e Tecnológico (FUNCAP) apoiou a realização da pesquisa derivada, em parte, no presente artigo, através da concessão da bolsa de doutorado ao autor, vinculada ao Programa de PósGraduação em Geografia da UFC.

Aos pareceristas da Revista Sociedade e Natureza pelas valiosas sugestões feitas ao texto original, as quais contribuíram consideravelmente para a melhoria do artigo.

\section{REFERÊNCIAS}

ALBERTÃO G.A., MARTINS JR. P.P. Estratos calcários da Pedreira Poty (Paulista), PE: evidências de evento catastrófico no primeiro registro do limite K-T descrito na América do Sul. In: WINGE M. et al. (Edit.) Sítios Geológicos e Paleontológicos do Brasil. Brasília: DNPM/CPRM - Comissão Brasileira de Sítios Geológicos e Paleobiológicos (SIGEP), v. 2, p. 277-290, 2009.

ALMEIDA, S. e PORTO JUNIOR, R. Projeto Ciclo das Rochas: um exemplo bem sucedido do uso do patrimônio geológico como estímulo ao aprendizado de ciências naturais. Anuário do Instituto de Geociências (UFRJ), v. 35, n. 1, p. 28-33, 2012. DOI: http://dx.doi.org/10.11137/2012_1_28_33

ALVES, C. C. E.; SIEBRA, F. S. F.; BEZERRA, L. M. A. e OLIVEIRA, M. L. T. Geopark Araripe: um estudo geoturístico e ambiental no geotope granito, Ceará/ Brasil. In: Anais do Seminário Latino Americano de Geografia Física e II Seminário Ibero Americano de Geografia Física. Coimbra: Universidade de Coimbra - Portugal, p. 1-9, 2010.

ARAÚJO, E. L. S. Geoturismo: conceptualização, implementação e exemplo de aplicação ao Vale do Rio Douro no Setor Porto-Pinhão. 2005. 219 f. Dissertação (Mestrado em Ciências do Ambiente). Escola de Ciências, Universidade do Minho, GuimarãesPortugal. 2005.

BARRETO, A. M. F.; ASSIS, H. M. B.; BEZERRA, F. H. R. e SUGUIO, K. Arrecifes, a Calçada do Mar de Recife, $P E$. In: WINGE M. et al. (Edit.) Sítios Geológicos e Paleontológicos do Brasil. Brasília: DNPM/CPRM - Comissão Brasileira de Sítios Geológicos e Paleobiológicos (SIGEP), v. 2, , 2009.

BARROS, J. S.; FERREIRA, R. V.; PEDREIRA, A. J. e GUIDON, N. Geoparque Serra da Capivara (PI). Proposta. In: SCHOBBENHAUS, C. e SILVA, C. R. (Org.) Geoparques do Brasil: propostas. Rio de Janeiro: CPRM, p. 493-542, 2012. 
BENTO, L. C. M. e RODRIGUES, S. C. Geoturismo em Unidades de Conservação: uma nova tendência ou uma necessidade real? Revista do Departamento de Geografia - USP, São Paulo-SP, v. 25, p. 77-97, 2013. DOI: http://dx.doi.org/10.7154/ RDG.2013.0025.0105

BENTO, L. C. M. e RODRIGUES, S. C. Geoturismo nas Quedas D’Água do Município de Indianapólis. Revista Mercator, Fortaleza-CE, v. 10, n. 21, p. 147-160, 2011. DOI: http://dx.doi.org/ 10.4215/ RM2011.1021.0010

BENTO, L. C. M. e ROdRIGUeS, S. C. O Geoturismo como instrumento em prol da divulgação, valorização e conservação do patrimônio natural abiótico - uma reflexão teórica. Revista Pesquisas em Turismo e Paisagens Cársticas, Campinas-SP, v. 2, n. 3, p. 55-65, 2010.

BENTO, L. C. M. e ROdRigues, S. C. Geomorfologia fluvial e Geoturismo. O potencial turístico de quedas d'água do município de Indianápolis, Minas Gerais. Revista Pesquisas em Turismo e Paisagens Cársticas, Campinas-SP, v. 1, n. 2, p. 59-70, 2009.

BÉTARD, F.; PEULVAST, J-P. e MAGALHÃES, A. O. Biodiversité, géodiversité et enjeux de leur conservation dans les montagnes humides du Nordeste brésilien. Bulletin De l'Association de Géographes Français, v.88, n.1, p.17-26., mar. 2011.

BORGATTI, L. e TOSATTI, G. Slope Instability Processes Affecting the Pietra Di Bismantova Geosite (Northern Apennines, Italy). Geoheritage, v. 2, p. 155168, 2010. DOI: $10.1007 / \mathrm{s} 12371-010-0023-8$

BRASIL. Casa Civil. Lei Federal no 9.795, de 27 de abril de 1999. Dispõe sobre a educação ambiental, institui a Política Nacional de Educação Ambiental e dá outras providências. Brasília, 1999.

BRASIL. Ministério do Turismo. Ecoturismo: orientações básicas. 2 ed. Brasília: MT, 2010.
BRILHA, J. Patrimônio geológico e geoconservação - a conservação da natureza na sua vertente geológica. Braga: Palimage, 2005.

BRITO, L. S. M.; PERINOTTO, A. R. C. Difusão da Ciência no Geopark Araripe, Ceará, Brasil. Anuário do Instituto de Geociências (UFRJ). v. 35, n.1, p. 42-48, 2012. DOI: http://dx.doi.org/10.11137/2012_1_42_48

CAPUTO, M. V. e PONCIANO, L. C. M. O. Pavimento Estriado de Calembre, Brejo do Piauí. In: WINGE, M. (Ed.) et al. Sítios Geológicos e Paleontológicos do Brasil. Brasília: CPRM, 2009.

CARCAVILLA, L.; DURÁN, J. J.; GARCÍACORTÉS, A. e LÓPEZ-MARTÍNEZ, J. Geological Heritage and Geoconservation in Spain: Past, Present, and Future. Geoheritage, v. 1, p. 75-91, 2009. DOI: http://dx.doi.org/10.1007/s12371-009-0006-9

CARVALHO, A. M.; CLAUDINO-SALES, V.; MAIA, L. P. e CASTRO, J. W. A. Eolianitos de Flecheiras/Mundaú, Costa Noroeste do Estado do Ceará, Brasil. In: WINGE, M. (Ed.) et al. Sítios Geológicos e Paleontológicos do Brasil. Vol. II. Brasília: CPRM, 2009.

CAVALCANTE, M. B. e FURTADO, E. M. Potencial geoturístico em unidades de conservação: um estudo do Parque Estadual da Pedra da Boca-PB. Revista GeoTextos, v. 7, n.1, p. 143-157, 2011.

CORATZA, P. e WAELE, J. D. Geomorphosites and Natural Hazards: teaching the importance of geomorphology in society. Geoheritage, v. 4, p. 195203, 2012. DOI: http://dx.doi.org/10.1007/s12371012-0058-0

DEGRANDI, S. M. e FIGUEIRÓ, A. S. Patrimônio natural e geoconservação: a geodiversidade do município gaúcho de Caçapava do Sul. Anais do VIII Congresso Nacional de Ecoturismo e do IV Encontro Interdisciplinar de Ecoturismo em Unidades de Conservação. Revista Brasileira de Ecoturismo, São Paulo, v. 4, n. 4, p. 515, 2011. 
DELPHIM, C. F. M. O Patrimônio natural do Brasil. Rio de Janeiro: IPHAN, 2004.

DOWLING, R. K. Geotourism's Global Growth. Geoheritage, v. 3, p.1-13, 2011. DOI: http://dx.doi. org/10.1007/s12371-010-0024-7

FARSANI, N. T.; COELHO, C. O. A. e COSTA, C. M. M. Analysis of Network Activities in Geoparks as Geotourism Destinations. International Journal of Tourism Research, v. 16, p.1-10, 2012. DOI: http:// dx.doi.org/10.1002/jtr.1879

FARSANI, N. T.; COELHO, C. O. A. e COSTA, C. Geotourism and Geoparks as novel strategies for socio-economic development in Rural Areas. International Journal of Tourism Research, v. 13, p. 68-81, 2011. DOI: http://dx.doi.org/10.1002/jtr.800

FAVERA, J. C. D. Parque Nacional de Sete Cidades, PI. In: SCHOBBENHAUS, C. (Ed.) et al. Sitios Geológicos e Paleontológicos do Brasil. Vol. I. Brasília: CPRM, 2002.

FERREIRA, V. P. e SIAL, A. N. Pico do Cabugi, $R N$. In: SCHOBBENHAUS, C. (Ed.) et al. Sítios Geológicos e Paleontológicos do Brasil. Vol. I. Brasília: CPRM, 2002.

FUERTES-GUTIÉRREZ, I. e FERNÁNDEZMARTÍNEZ, E. Geosites Inventory in the Leon Province (Northwestern Spain): A Tool to Introduce Geoheritage into Regional Environmental Management. Geoheritage, n. 2, p. 57-75, 2010. DOI: http://dx.doi.org/10.1007/s12371-010-0012-y

GIL, A. C. Como elaborar projetos de pesquisa. 3 ed. São Paulo: Atlas, 1996.

GODOY, L. H.; SARDINHA, D. S.; BERTINI, R. J.; CONCEIÇÃO, F. T.; DEL ROVERI, C. e MOREIRA, C. A. Potencial Geoparque de Uberaba (MG): geodiversidade e geoconservação. Revista Sociedade e Natureza. Uberlândia-MG, v. 2, n. 25, p. 395-410, 2013.
GRAY, M. Geodiversity: Valuing and Conserving Abiotic Nature. Chichester-England: John, Wiley \& Sons, 2004.

JOYCE, E. B. Australia's Geoheritage: History of Study, A New Inventory of Geosites and Applications to Geotourism and Geoparks. Geoheritage, v. 2, p. 39-56, 2010. DOI: http://dx.doi.org/ 10.1007/s12371010-0011-z

JULIO, K.; MAGINI, C.; MAIA, L. P. e CASTRO, J. W. A. Ponta de Jericoacoara, CE. In: WINGE, M. (Ed.) et al. Sitios Geológicos e Paleontológicos do Brasil. Vol. II. Brasília: CPRM, 2009.

KELLNER, A. W. A. Membro Romualdo da Formação Santana, Chapada do Araripe, CE. In: SCHOBENHAUS. (Ed.) et al. Sítios Geológicos e Paleontológicos do Brasil. Brasília: CPRM, 2002.

LAGES, G. A.; MARINHO, M. S.; NASCIMENTO, M. A. L.; MEDEIROS, V. C.; DANTAS, E. L. e FIALHO, D. A. Mar de Bolas do Lajedo do Pai Mateus, Cabaceiras, PB. In: WINGE, M. (Ed.) et al. Sítios Geológicos e Paleontológicos do Brasil. Vol. II. Brasília: CPRM, 2009.

LEONARDI, G. e CARVALHO, I. S. Icnofósseis da Bacia do Rio do Peixe, PB. In: SCHOBENHAUS. (Ed.) et al. Sítios Geológicos e Paleontológicos do Brasil. Brasília: CPRM, 2002.

LOBO, H. A. S.; MOREIRA, J. C. e FONSECA FILHO, R. E. Geoturismo e Conservação do Patrimônio Natural em áreas cársticas brasileiras. In: SEMINÁRIO DA ASSOCIAÇÃO NACIONAL PESQUISA E PÓS-GRADUAÇÃO EM TURISMO, 9., 2012, São Paulo-SP. 2012. Anais do IX Seminário Da Associação Nacional Pesquisa E Pós-Graduação Em Turismo. São Paulo, 2012.

LOPES, L. S. O; ARAÚJO, J. L. e CASTRO, A. J. F. Geoturismo: Estratégia de geoconservação e desenvolvimento local. Revista Caderno de Geografia, v. 21, n. 35, 2011 . 
LUGERI, F. R.; AMADIO, V.; BAGNAIA, R.; CARDILLO, A. e LUGERI, N. Landscapes and Wine Production Areas: a Geomorphological Heritage. Geoheritage, v. 3, p. 221-232, 2011. DOI: http:// dx.doi.org/10.1007/s12371-011-0035-z

LUGON, R.; PRALONG, J-P. e REYNARD, E. Patrimoine culturel et géomorphologie: le cas valaisan de quelques blocs erratiques, d'une marmite glaciaire et d'une moraine. Bulletin Murithienne, v. 124, p.7387, 2006.

MARIANO, G.; CORREIA, P. B.; FERREIRA. R. V.; e ACCIOLY, A. C. A. Pedra Furada de Venturosa, PE. In: WINGE, M. (Ed.) et al. Sítios Geológicos e Paleontológicos do Brasil. Vol. II. Brasília: CPRM, 2009.

MEDEIROS, W. D. A. e OLIVEIRA, F. F. G. Geodiversidade, Geopatrimônio e Geoturismo em Currais Novos, NE do Brasil. Revista Mercator. Fortaleza-CE, v. 10, n. 23, p. 59-69, 2011. DOI: http:// dx.doi.org/10.4215/RM2011.1023.0005

MICCADEI, E.; PIACENTINI, T. e ESPOSITO, G. Geomorphosites and Geotourism in the Parks of the Abruzzo Region (Central Italy). Geoheritage, v. 3, p. 233-251, 2011. DOI: http://dx.doi.org/10.1007/ s12371-011-0037-x

MOCHIUTTI, N. F.; GILSON BURIGO GUIMARÃES, G. B.; MOREIRA, J. C.; LIMA, F. F. e FREITAS, F. I. Os Valores da Geodiversidade: Geossítios do Geopark Araripe/CE. Anuário do Instituto de Geociências (UFRJ), v. 35, n.1, p. 173-189, 2012. DOI: http://dx.doi.org/10.11137/2012_1_173_189

MOREIRA, J. C. Geoturismo: uma abordagem histórico-conceitual. Revista Pesquisas em Turismo e Paisagens Cársticas, Campinas-SP, v. 3, n. 1, p. 5-10, 2010.

NASCIMENTO, M. A. L. e FERREIRA, R. V. Geoparque Seridó (RN). Proposta. In: SCHOBBENHAUS, C. e SILVA, C. R. (Org.) Geoparques do Brasil: propostas. p. 361-416 Rio de Janeiro: CPRM, 2012.
NASCIMENTO, M. A. L.; FERREIRA, R. V. e WILDNER, W. Geoparque Litoral Sul de Pernambuco (PE). Proposta. In: SCHOBBENHAUS, C. e SILVA, C. R. (Org.) Geoparques do Brasil: propostas. Rio de Janeiro: CPRM, p. 647-686, 2012.

NASCIMENTO, M. A. L.; RUCHKYS, U. A. e MANTESSO-NETO, V. Geoturismo: um novo segmento do turismo no Brasil. Revista Global Tourism, v. 3, n. 2, 2007.

PANIZZA, M. Geomorphosites: Concepts, methods and examples of geomorphological survey. Chinese Science Bulletin, v. 46, Supp, p. 4-5, 2001. DOI: http:// dx.doi.org/10.1007/BF03187227

PANIZZA, M. e PIACENTE, S. Geomorphosites and Geotourism. Revista Geográfica Acadêmica, v. 2, n. 1, p. 05-09, 2008. DOI: http://dx.doi.org/10.1007/ s12371-011-0041-1

PELLITERO, R.; GONZÁLEZ-AMUCHASTEGUI, M. J.; RUIZ-FLAÑO, P. e SERRANO, E. Geodiversity and Geomorphosite Assessment Applied to a Natural Protected Area: the Ebro and Rudron Gorges Natural Park (Spain). Geoheritage, v. 3, p. 163-174, 2011. DOI: http://dx.doi.org/10.1007/s12371-010-0022-9

PEREIRA, P.; PEREIRA, D. I. e ALVES, M. I. C. Avaliação do Património Geomorfológico: proposta de metodologia. Publicações da Associação Portuguesa de Geomorfólogos - APGeom, Lisboa-POR, v. 5, p. 235-247, 2007. DOI: http://hdl.handle.net/1822/7406

PIRANHA, M. J.; DEL LAMA, E. A. e BACCI, D. L. C. Geoparks in Brazil: strategy of Geoconservation and Development. Geoheritage, n. 3, p. 289-298, 2011. DOI: http://dx.doi.org/10.1007/s12371-0110043-z

PONCIANO, L. C. M. A.; FONSECA, V. M. M.; FERNANDES, A. C. S.; MACHADO, D. M. C. e SOUZA, A. R. Afloramento Fossilífero de Oiti, Bacia do Parnaíba, PI. In: WINGE, M. (Ed.) et al. Sítios Geológicos e Paleontológicos do Brasil. Brasília: CPRM, 2009. 
PORPINO, K. O.; SANTOS JR., V. e SANTOS, M. F. C. F. Lajedo de Soledade, Apodi, RN. In: WINGE, M. (Ed.) et al. Sitios Geológicos e Paleontológicos do Brasil. Vol. II. Brasília: CPRM, 2009.

ROCHA, J. C. A. D. e NASCIMENTO, M. A. L. O Pico do Cabugi como produto ecoturístico e geoturístico no Rio Grande do Norte. Revista Global Tourism, v. 3, n. 2, 22 p., 2007.

ROCHA, A. J.D. e PEDREIRA, A. J. Geoparque Morro do Chapéu (BA). Proposta. In: SCHOBBENHAUS, C. e SILVA, C. R. (Org.) Geoparques do Brasil: propostas. Rio de Janeiro: CPRM, p. 59-110, 2012.

RUSS, B. R. e NOLASCO, M. C. Revelando a Geodiversidade Através da Educação Ambiental: Percepção de Estudantes Sobre o Geossítio Manga do Céu. Anuário do Instituto de Geociências (UFRJ), v. 35, n.1, p. 271-280, 2012. DOI: http://dx.doi. org/10.11137/2012_1_271_280

SANTOS, M. F. C. F.; LIMA FILHO, L. P. e BERGQVIST, L. P. Fósseis pleistocênicos da ravina do Leon, Lajedo de Soledade, Apodi/RN. Revista de Geologia, Fortaleza-CE, v. 15, p. 22-29, 2002.

SCHOBBENHAUS, C. e SILVA, C. R. O papel do Serviço Geológico do Brasil na criação de geoparques e na conservação do patrimônio geológico. In: SCHOBBENHAUS, C. e SILVA, C. R. (Org.) Geoparques do Brasil: propostas. Rio de Janeiro: CPRM, 2012.

SILVA, J. B. Educação Ambiental. In: CLAUDINOSALES, V. (Org) Ecossistemas Brasileiros: Manejo e Conservação. Fortaleza: Expressão Gráfica e Editora, 2003.

SILVA, J. R. B. e PERINOTTO J. A. J. O geoturismo na geodiversidade de Paraguaçu Paulista como modelo de geoconservação das estâncias. Revista Global Tourism, v. 3, n. 2, 40 p., 2007.

SOUSA, D. C. e NASCIMENTO, M. A. L. Geoturismo no litoral de Icapuí/CE (NE do Brasil): uma alternativa de divulgação do patrimônio geológico. Revista de Geologia, Fortaleza-CE, v. 20, n 2, p. 279-287, 2007.

SOUSA, D. C. et al. Falésias na Praia de Ponta Grossa, Icapuí, CE. In: WINGE, M. (Ed.) et al. Sitios Geológicos e Paleontológicos do Brasil. Brasília: CPRM, 2009.

VIANA, M. S. S. e NEUMANN, V. H. L. Membro Crato da Formação Santana,Chapada do Araripe, CE. In: SCHOBENHAUS. (Ed.) et al. Sítios Geológicos e Paleontológicos do Brasil. Brasília: CPRM, 2002.

VIEIRA, A. B. e CUNHA, L. Património Geomorfológico: tentativa de sistematização. In: SEMINÁRIO LATINO AMERICANO DE GEOGRAFIA FÍSICA, 3., 2004, Puerto Vallarta México. Actas do III Seminário Latino Americano de Geografia Física, Puerto Vallarta, 2004.

WILDNER, W. e FERREIRA, R. V. Geoparque Fernando de Noronha (PE). Proposta. In: SCHOBBENHAUS, C. e SILVA, C. R. (Org.) Geoparques do Brasil: propostas. Rio de Janeiro: CPRM, p. 317-360, 2012.

XIMENES, C. L. Tanques Fossilíferos de Itapipoca, CE. In: WINGE, M. (Ed.) et al. Sítios Geológicos e Paleontológicos do Brasil. Brasília: CPRM, 2009.

ZGŁOBICKI, W. e BARAN-ZGŁOBICKA, B. Geomorphological Heritage as a Tourist Attraction. A Case Study in Lubelskie Province, SE Poland. Geoheritage, v. 5, p. 137-149, 2013. DOI: http:// dx.doi.org/10.1007/s12371-013-0076-6 